\title{
The importance of AED placement and accessibility on chance of bystander defibrillation of out-of-hospital cardiac arrest
}

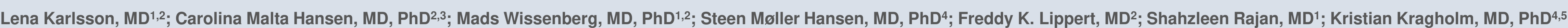
Sidsel G. Møller, MD1; Kathrine Bach Søndergaard, MD¹; Gunnar H. Gislason, MD, PhD 1,6,7; Christian Torp-Pedersen, MD, DSc ${ }^{4,5,8}$; Fredrik Folke, MD, PhD ${ }^{1,2}$

Department of Cardiology, Copenhagen University Hospital Gentofte, Hellerup, Denmark; ${ }^{2}$ Emergency Medical Services Copenhagen, University of Copenhagen, Denmark; ${ }^{3}$ Department of Cardiology, Nephrology, and Endocrinology, Nordsjællands Hospital Hillerød, University of Copenhagen, Denmark: 4 Unit of Epidemiology and Biostatistics. Aalborg University Hospital, Aalborg Denmark: 5 Department of Cardiology Aalborg University Hospital, Aalborg, Denmark: 6 The National Institute of Public Health, University of Southern Denmark, Copenhagen Denmark; ${ }^{7}$ The Danish Heart Foundation, Copenhagen, Denmark; ${ }^{8}$ The Department of Health Science and Technology, Aalborg University, Aalborg, Denmark

BACKGROUND: Despite a marked increase in the dissemination of publicly available automated external defibrillators (AEDs), defibrillation of out-of-hospital cardiac arrests (OHCAs) prior to arrival of the EMS has remained low, around $2 \%-4 \%$. AEDs are frequently inaccessible when most OHCA occur (e.g. outside normal working hours), however, knowledge of the impact of inaccessibility of AEDs on bystander defibrillation and survival remains sparse. PURPOSE: To examine how AED placement and AED accessibility affect bystander defibrillation and survival in OHCA.
METHODS: We identified all OHCAs registered by the physician manned Copenhagen Mobile Emergency Care Unit (2008-2016), and all publicly available registered AEDs in Copenhagen (2007-2016) from the Danish AED Network. All OHCAs and AEDs were geocoded, and the route distances between OHCAs and AEDs were calculated. A covered OHCA was defined as an OHCA with an AED located $\leq 200 \mathrm{~m}$, and AED accessibility was assessed for every AED at the time of OHCA. AED coverage according to type of AED location as well as the likelihood of bystander defibrillation and 30-day survival were examined.

\section{RESULTS}

- 1830 registered AEDs (2008 through 2016)

- Of 2500 OHCAs, $22.6 \%(n=566)$ were covered by an AED $\leq 200 m$ route distance

Table 1. Loss of AED coverage, due to limited AED accessibility, according to AED location

\begin{tabular}{|c|c|c|c|}
\hline AED location & $\begin{array}{l}\text { All OHCAs } \\
\text { located } \leq 200 \mathrm{~m} \text { of } \\
\text { an AED, } n(\%)\end{array}$ & $\begin{array}{l}\text { OHCAs located } \\
\leq 200 \mathrm{~m} \text { of accessible } \\
\text { AEDs, } n(\%)\end{array}$ & $\begin{array}{l}\text { Coverage loss due } \\
\text { to AED } \\
\text { inaccessibility, } n \text { (\%) }\end{array}$ \\
\hline Total & $566(100.0)$ & $276(48.8)$ & $290(51.2)$ \\
\hline Transportation facility & $12(2.1)$ & $10(83.3)$ & $2(16.7)$ \\
\hline Residential settings & $38(6.7)$ & $31(81.6)$ & $7(18.4)$ \\
\hline Church/community centre & $5(0.9)$ & $4(80.0)$ & $1(20.0)$ \\
\hline Hotels and conference venues & $13(2.3)$ & $9(69.2)$ & $4(30.8)$ \\
\hline Sports facility & $73(12.9)$ & $42(57.5)$ & $31(42.5)$ \\
\hline Other & $37(6.5)$ & $20(54.1)$ & $17(46.0)$ \\
\hline Shopping malls/shops/banks & $45(8.0)$ & $24(53.3)$ & $21(46.7)$ \\
\hline Attractions/recreational areas & $21(3.7)$ & $11(52.4)$ & $10(47.6)$ \\
\hline Companies/offices & $105(18.6)$ & $52(49.5)$ & $53(50.5)$ \\
\hline Public building & $36(6.4)$ & $16(44.4)$ & $20(55.6)$ \\
\hline Union/association & $35(6.2)$ & $12(34.3)$ & $23(65.7)$ \\
\hline School/education facility & $75(13.3)$ & $25(33.3)$ & $50(66.7)$ \\
\hline Health clinics & $71(12.5)$ & $20(28.2)$ & $51(71.8)$ \\
\hline
\end{tabular}

Figure 1. Bystander defibrillation and 30-day survival among OHCAs covered by an accessible AED vs. an inaccessible AED
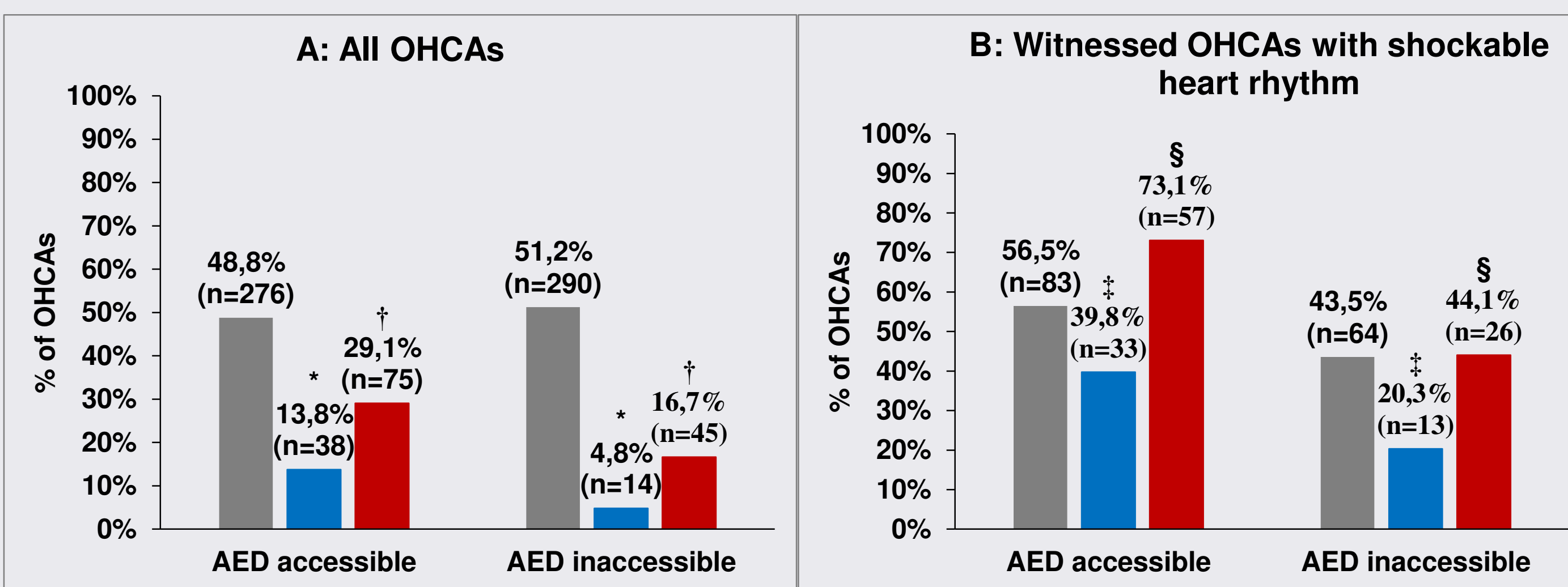

OHCAs covered by an AED $\leq 200 \mathrm{~m} \quad$ Bystander defibrillation $\quad$ 30-day survival

(A) all OHCAs ( $n=566$ ). " $\mathrm{P}<0.05$ for bystander defibrillation. $\mathrm{tP}<0.05$ for 30 -day survival; however, 38 OHCAs had missing information on survival status; therefore, the percentages for survival data are based on $n=258$ for accessible AEDs, and $n=270$ for inaccessible AEDs. (B) a subgroup of witnessed OHCAs with shockable heart rhythm $(n=147) . \pm P<0.05$ for bystander defibrillation. ${ }^{\mathrm{S} P}<0.05$ for 30 -day survival; however, 10 OHCAs had missing information on survival status; therefore,
the percentages for survival data are based on $\mathrm{n}=78$ for accessible $\mathrm{AEDs}$, and $\mathrm{n}=59$ for inaccessible AEDs.

\section{CONCLUSIONS}

AED accessibility was highly dependent on AED location. The chance of bystander defibrillation was tripled, and 30-day survival almost doubled, when the nearest AED was accessible, compared to inaccessible, at the time of OHCA. 